\title{
NÍVEIS DE CÁLCIO E AVALIAÇÃO ÓSSEA E DE OVOS DE AVESTRUZES REPRODUTORAS
}

\author{
CALCIUM LEVELS AND EVALUATION OF BONE AND EGG IN BREEDING OSTRICHES
}

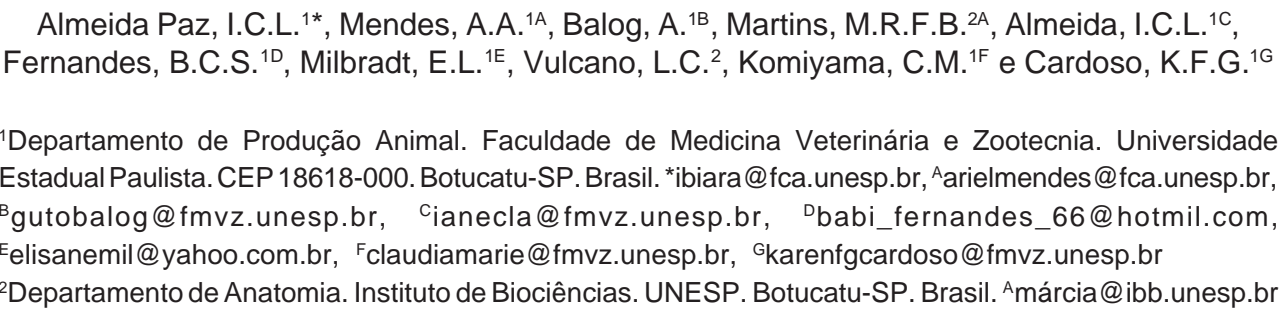

PaLAVRAS CHAVE ADICIONAIS

Qualidade de osso. Nutrição. Postura. Produção.

\section{RESUMO}

Realizaram-se análises da densidade óssea em tíbias e fêmures de 6 casais de avestruzes reprodutoras com idade entre 5 a 7 anos, alimentados durante 8 semanas, 3 casais com ração de reprodução (T1), e 3 casais com ração de manutenção (T2). Verificou-se que a produção de ovos não foi afetada pelas dietas, assim como a qualidade da casca dos ovos. No entanto a qualidade dos ossos foi pior para as aves do T2.

\section{SUMMARY}

Analyse of mineral density in tibias and femurs of breeder ostriches had been carried on six couples 5-7 years old. During 8 weeks, 3 couples had been fed with ration of reproduction (T1) and other 3 couples with ration of maintenance (T2). It was possible to verify that the egg production was not affected by the diets, as well as the quality of egg shells. However the quality of the bones was worse for the birds fed of T2.

\section{INTRODUÇÃO}

O estudo da densidade mineral óssea (DMO) de aves de interesse zootécnico, favorece a melhor compreensão e avaliação do processo de mineralização óssea. A DMO pode ainda, ser medida através de técnicas como a composição mineral óssea, resis-

Recibido: 10-1-08. Aceptado: 1-4-08.

\author{
ADDITIONAL KEYWORDS \\ Bone quality. Nutrition. Laying. Production.
}

tência óssea à quebra, índice Seedor (Seedor, 1995), etc. O desenvolvimento ósseo está ligado ao aporte nutricional das dietas. O suprimento de cálcio para a casca dos ovos está ligado à sua disponibilidade no trato gastrintestinal e quando este mineral não é disponibilizado pela dieta, é obtido dos ossos. Objetivou-se avaliar qual é a contribuição do cálcio e fósforo ósseos na formação da casca dos ovos.

\section{MATERIAL E MÉTODOS}

Utilizaram-se 6 casais de avestruzes (57 anos); cada ave recebeu 2 kg de ração ao dia durante 8 semanas. Os machos foram mantidos junto às fêmeas para estimular a postura. Os tratamentos utilizados foram: T1: 3 casais com ração com nível adequado de cálcio (ração de reprodução) e T2: 3 casais com ração com nível baixo de cálcio (ração de manutenção). Usaram-se rações comerciais, sendo T1: 88,09\% de matéria seca (MS); 17,47\% de proteína bruta (PB); $2600 \mathrm{kcal} / \mathrm{kg}$ de energia metabolizável (EM); 4,21\% extrato etéreo (EE); 7,28\% de minerais totais (MIN); 0,93\% de cálcio(Ca); 0,46\% de fósforo disponível (Pd) e 7,93\% de fibra 
ALMEIDAPAZETAL.

Tabela I. Produção, peso e qualidade da casca de ovos de avestruzes alimentados com dietas distintas. (Egg production and shell egg quality of ostriches feeding two diets).

\begin{tabular}{lcccccc}
\hline Tratamento & $\begin{array}{c}\text { Postura } \\
\%\end{array}$ & $\begin{array}{c}\text { Peso ovo } \\
(\mathrm{g})\end{array}$ & $\begin{array}{c}\text { Peso casca } \\
(\mathrm{g})\end{array}$ & $\begin{array}{c}\text { Casca } \\
\%\end{array}$ & $\begin{array}{c}\text { Ca } \\
\mathrm{mg} / \mathrm{g}\end{array}$ & $\begin{array}{c}\mathrm{P} \\
\mathrm{mg} / \mathrm{g}\end{array}$ \\
\hline Ração de manutenção & $58,4 \pm 2,22^{\mathrm{A}}$ & $1529 \pm 138^{\mathrm{B}}$ & $247 \pm 30^{\mathrm{B}}$ & $16,1 \pm 0,5^{\mathrm{A}}$ & $375 \pm 0,5^{\mathrm{B}}$ & $1,61 \pm 0,5^{\mathrm{A}}$ \\
Ração de reprodução & $63,7 \pm 3,4^{\mathrm{A}}$ & $1748 \pm 244^{\mathrm{A}}$ & $267 \pm 28^{\mathrm{A}}$ & $15,3 \pm 0,7^{\mathrm{B}}$ & $397 \pm 1^{\mathrm{A}}$ & $1,61 \pm 0,2^{\mathrm{A}}$
\end{tabular}

Médias seguidas por letras diferentes, na coluna, diferem entre si, pelo teste $F(p<0,05)$.

bruta (FB), e T2: 89,03\% MS; 18,17\% PB; $2506 \mathrm{kacl} / \mathrm{kg} \mathrm{EM}$; 3,97\% EE; 11,15\% MIN; 3,48\% Ca; $1,70 \%$ Pd e 7,46\% FB. As fêmeas foram abatidas em um abatedouro comercial e radiografadas, logo após o abate, na epífise proximal da tíbia e distal do fêmur direito. A técnica radiográfica utilizada foi $65 \mathrm{kVp} \mathrm{x}$ $3 \mathrm{mAs}$, com distância foco filme de $90 \mathrm{~cm}$. As análises de resistência óssea foram efetuadas com o aparelho de teste de ensaio EMIC DL 10000, o qual foi regulado para permitir o vão livre de $10 \mathrm{~cm}$. Índice Seedor: peso do osso fresco/maior comprimento. Oteor de matéria seca (Kim et al., 2004) e minerais totais (Rath et al., 1999) foram avaliados após à análise de resistência óssea. O cálcio foi determinado por espectrofotometria de absorção atômica e o P por colorimetria. A análise estatística foi objetivada com o pacote estatístico SAEG (1998) - ANOVA. As correlações foram realizadas através do teste de Pearson, todas as análises tiveram nível de 95\% de probabilidade.

\section{RESULTADOSDISCUSSÃO}

Foi possível verificar (tabela I) que a produção de ovos não foi afetada pela ração, porém, o peso dos ovos e da casca foram maiores $(\mathrm{p}<0,05)$ para as aves que receberam ração de reprodução. A porcentagem de casca foi menor para os ovos destas aves, pois o volume dos ovos aumentou em relação ao peso da casca. Constatou-se também que a quantidade de Ca na casca foi maior para as aves que receberam ração de reprodução, já a quantidade de $\mathrm{P}$ na casca dos ovos não foi afetada pelos tratamentos, provavelmente, porque a sua contribuição para a sua formação é bem menor que a do cálcio. As aves alimentadas com ração de reprodução apresentaram melhor qualidade óssea que aquelas alimentadas com ração de manutenção. Em decorrência da escassez

Tabela II. Características de qualidade óssea das tíbias e fêmures das avestruzes submetidas a duas dietas. (Characteristics of quality of the tibias and femurs of ostriches feeding two diets).

\begin{tabular}{|c|c|c|c|c|c|c|c|}
\hline & $\mathrm{RO}\left(\mathrm{kgf} / \mathrm{cm}^{2}\right)$ & IS & MS (\%) & MIN (\%) & $\mathrm{DMO}(\mathrm{mmAl})$ & $\mathrm{Ca}(\mathrm{mg} / \mathrm{g})$ & $P(\mathrm{mg} / \mathrm{g})$ \\
\hline \multirow{2}{*}{$\begin{array}{l}\text { Tíbia } \\
\text { manutenção } \\
\text { reprodução }\end{array}$} & $623,2 \pm 36^{B}$ & $0,06 \pm 0,2^{A}$ & $79,8 \pm 1^{\mathrm{B}}$ & $47,8 \pm 0,3^{\mathrm{B}}$ & $11,4 \pm 0,3^{\mathrm{B}}$ & $376,3 \pm 0,4^{\mathrm{B}}$ & $135,0 \pm 1^{\mathrm{B}}$ \\
\hline & $868,1 \pm 98^{A}$ & $0,06 \pm 0,2^{A}$ & $83,2 \pm 2^{A}$ & $52,4 \pm 0,7^{A}$ & $16,0 \pm 0,5^{A}$ & $398,6 \pm 0,3^{A}$ & $162,0 \pm 0,3^{A}$ \\
\hline \multicolumn{8}{|l|}{ Fêmur } \\
\hline manutenção & $214,1 \pm 43^{B}$ & $0,07 \pm 0,1^{A}$ & $72,5 \pm 0,2^{B}$ & $44,15 \pm 0,7^{\mathrm{B}}$ & $5,9 \pm 0,4^{\mathrm{B}}$ & $364,6 \pm 4^{\mathrm{B}}$ & $124,7 \pm 0,8^{B}$ \\
\hline reprodução & $377,4 \pm 60^{A}$ & $0,08 \pm 0,1^{\mathrm{A}}$ & $80,2 \pm 0,1^{A}$ & $45,9 \pm 0,6^{A}$ & $7,9 \pm 0,5^{A}$ & $385,9 \pm 0,7^{A}$ & $148,8 \pm 0,9^{A}$ \\
\hline
\end{tabular}

Médias seguidas por letras diferentes, na coluna, diferem entre si, pelo teste $F(p<0,05)$. $R O=$ resistência óssea, IS= índice Seedor, MS= matéria seca, MIN= minerais totais, $\mathrm{DMO}=$ densidade mineral óssea.

Archivos de zootecnia vol. 59, núm. 227, p. 460. 


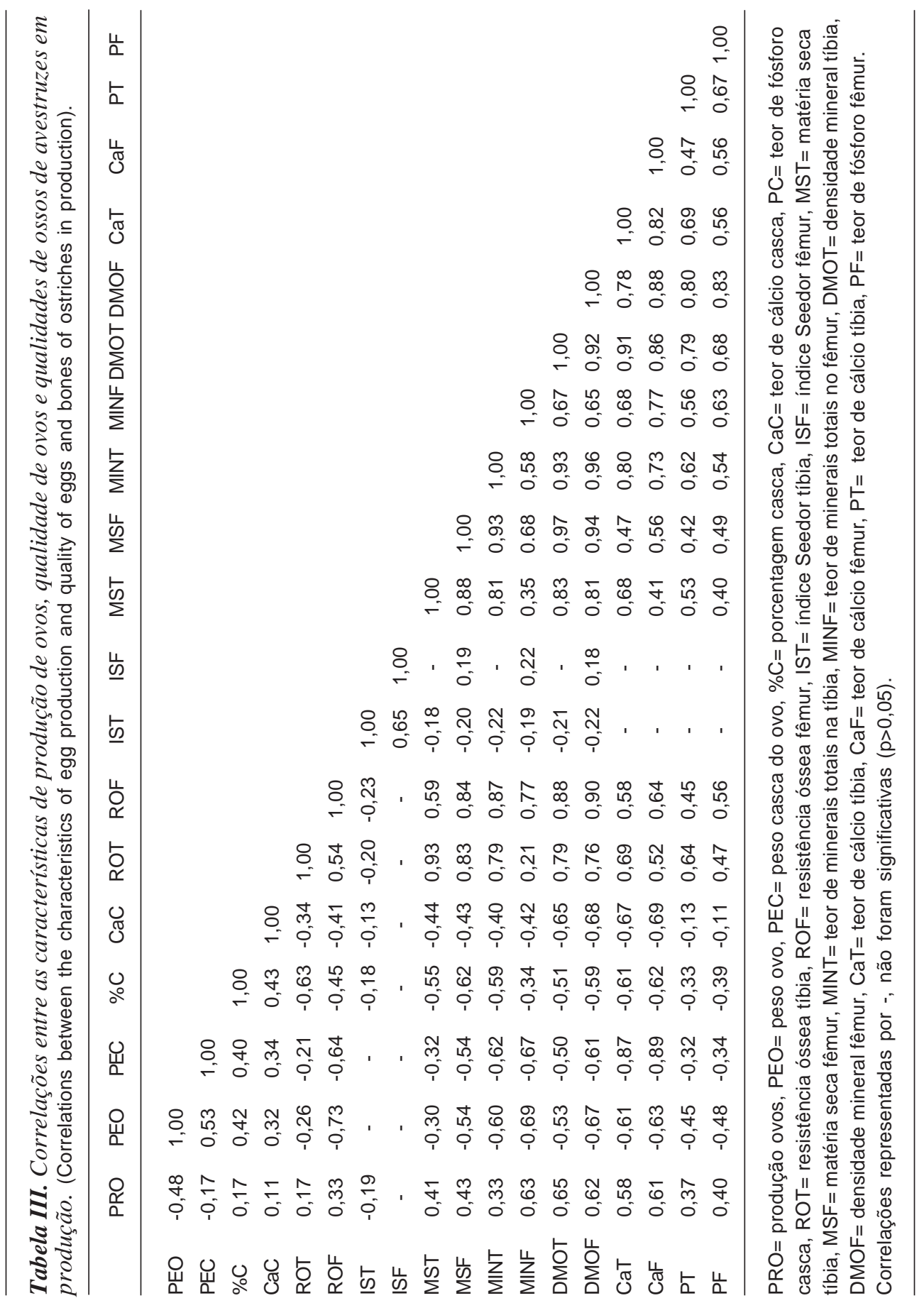


de trabalhos sobre a qualidade de ovos e ossos de avestruzes, a discussão dos resultados obtidos fundamentou-se em trabalhos com outras aves. Resultados semelhantes aos encontrados neste experimento foram também, relatados por vários autores, ao estudarem galinhas poedeiras e matrizes pesadas de frangos de corte (Robinson et al., 1993; Oliveira et al., 2002; Shaver Brown, 2005; Almeida Paz e Bruno, 2006), verificando que a deficiência de cálcio na dieta afeta a princípio a qualidade dos ossos e depois a qualidade da casca dos ovos. Na tabela II estão os valores para a qualidade das tíbias e fêmures. As correlações entre postura, qualidade de casca de ovos e ossos estão na tabela III. Estas correlações demonstram que a qualidade de ossos está intimamente correlacionada com a qualidade da casca dos ovos e a sua produção. Verificaram-se correlações negativas entre a qualidade de ossos e a qualidade da casca de ovos. Entre

\section{BIBLIOGRAFIA}

Almeida Paz, I.C.L., Mendes, A.A., Takita, T.S., Vulcano, L.C. and Garcia, R.G. 2005. Comparision of tecnhiques for tibial dyscondroplasia assessment in broiler chickens. Braz. J. Poultry Sci., 7: 27-32.

Almeida Paz, I.C.L. and Bruno, L.D.G. 2006. Bone mineral density: review. Braz. J. Poultry Sci., 8: 69-74.

Almeida Paz, I.C.L., Mendes, A.A., Balog, A., Almeida, I.C.L., Vulcano, L.C. e Komiyama, C.M. 2007. Caracterização da degeneração femoral em frangos de corte por meio da densidade mineral óssea. Em: Conferência APINCO. FACTA. Santos. Suplemento da Braz. J. Poultry Sci., p. 1.

Kim, W.K., Monalson, L. and Herrer, P. 2004. Effects of different bone preparation methods (fresh, dry, and fat-free dry) on bone parameters and the correlations between bone breaking strength and the other bone parameters. Poultry Sci., 83: 1663-1666. as características de qualidade óssea podese afirmar que as correlações são positivas entre as características de tíbias e fêmures e também entre as características nos mesmos ossos, ou seja, estas características estão muito ligadas entre si. Isto não ocorreu apenas, para o Índice Seedor, principalmente de fêmures, que não apresentou correlações entre as demais características. Resultados semelhantes a estes foram encontrados em estudos prévios. Segundo Almeida Paz et al. (2005), a qualidade óssea de matrizes pesadas é afetada a partir de um limiar de produção de ovos. Isto também é observado em poedeiras (Almeida Paz et al., 2007).

En conclução uma ração com baixos níveis de Ca afeta a qualidade dos ossos, interferindo pouco na qualidade da casca dos ovos, sem afetar a postura. A taxa de $\mathrm{Ca}$ e $\mathrm{P}$ nos ossos é suficiente para suprir as necessidades das avestruzes sem prejudicar muito a postura e a qualidade dos ovos.

Oliveira, J.R., Bertechini, A.G. e Fassini, E.J. 2002. Níveis de cálcio para poedeiras leves e semipesadas no segundo ciclo de produção. Ciência e Agrotecnol., 26: 1060-1067.

Rath, N.C., Balog, J.M. and Huff, W.E. 1999. Comparative differences in the composition and biomechanical properties of tibiae of seven and seventy weeks old male and female broiler breeder chickens. Poultry Sci., 78: 1232-1239.

Robinson, F.E., Wilson, J.L. and Yu, M.W. 1993. The relationship between body weight and reproductive efficiency in meat-type chickens. Poultry Sci., 72: 912-922.

SAEG. 1998. Sistema análise estatística e genética. Manual de utilização do programa SAEG. Viçosa. 59 pp.

Seedor, J.G. 1995. The biophosphanate alendronate (MK-217) inhibit bone loss due to ovariectomy in rats. J. Bone Miner. Res., 4: 265- 270.

Shaver Brown. 2005. Guía de manejo de ponedoras. www.isapoultry.com (02/02/06). 26 pp.

Archivos de zootecnia vol. 59, núm. 227, p. 462. 